\title{
Assessment of viral RNA in idiopathic pulmonary fibrosis using RNA-seq
}

Qinyan Yin ${ }^{1}$, Michael J. Strong ${ }^{2}$, Yan Zhuang ${ }^{1}$, Erik K. Flemington ${ }^{2}$, Naftali Kaminski ${ }^{3}$, Joao A. de Andrade ${ }^{4}$ and Joseph A. Lasky ${ }^{1 *}$

\begin{abstract}
Background: Numerous publications suggest an association between herpes virus infection and idiopathic pulmonary fibrosis (IPF). These reports have employed immunohistochemistry, in situ hybridization and/or PCR, which are susceptible to specificity artifacts.

Methods: We investigated the possible association between IPF and viral RNA expression using next-generation sequencing, which has the potential to provide a high degree of both sensitivity and specificity. We quantified viral RNA expression for 740 viruses in 28 IPF patient lung biopsy samples and 20 controls. Key RNA-seq results were confirmed using Real-time RT-PCR for select viruses (EBV, HCV, herpesvirus saimiri and HERV-K).

Results: We identified sporadic low-level evidence of viral infections in our lung tissue specimens, but did not find a statistical difference for expression of any virus, including EBV, herpesvirus saimiri and HERV-K, between IPF and control lungs.

Conclusions: To the best of our knowledge, this is the first publication that employs RNA-seq to assess whether viral infections are linked to the pathogenesis of IPF. Our results do not address the role of viral infection in acute exacerbations of IPF, however, this analysis patently did not support an association between herpes virus detection and IPF.
\end{abstract}

Keywords: Idiopathic pulmonary fibrosis, IPF, RNA-seq, Viruses, EBV, HCV, HERV-K, Herpesvirus saimiri

\section{Background}

Idiopathic pulmonary fibrosis (IPF) is a progressive disease with insidious onset in older people that progresses relentlessly in the absence of therapy to disability and death [1]. Although multiple risk factors, including viral infection, have been linked to IPF, studies are inconsistent and its etiology remains unclear. To date, more than 14 viruses have been investigated for a potential role in initiation and progression of IPF, including RNA viruses such as Hepatitis C (HCV), and DNA viruses such as human herpes viruses (HHVs), adenoviruses, human

\footnotetext{
* Correspondence: jlasky@tulane.edu

${ }^{1}$ Section of Pulmonary Diseases, Critical Care and Environmental Medicine, Department of Medicine, Tulane University School of Medicine, 1430 Tulane Avenue, New Orleans, LA 70112, USA

Full list of author information is available at the end of the article
}

endogenous retrovirus E (HERV-E), transfusion transmitted virus (TTV) and parvovirus B19 [2-7]. However, the studies on the relationship between virus expression and development of IPF are conflicting. While some studies show that virus infection is associated with IPF, other manuscripts show no viral association with IPF [8-11], which may be due to the differences in virus distribution and sensitivity and/or specificity of the techniques employed between studies.

Given the fact that alveolar epithelial cells are abnormal and likely contribute to the pathobiology of IPF, we believe that epithelial perturbation may contribute to inducing and maintaining IPF. Herpes viruses can infect many different cell types, including epithelial cells with two infection stages, the lytic stage and the latent stage. 
Both lytic genes and latent genes could interact with cellular genes to contribute to IPF initiation, progression and/or maintenance. Viral genes may regulate cellular gene expression and induce fibrogenesis. For example, Type I collagen can be induced by adenovirus [12]. HSV-1 stimulates endoplasmic reticulum (ER) stress and apoptosis [3], and these processes are implicated in the pathobiology of IPF. HCMV infection induces the unfolded protein response (UPR) and it's related signaling pathways elF2alpha kinase PERK, and causes endoplasmic reticulum stress [13]. CMV, KSHV and EBV also induce endoplasmic reticulum stress and the UPR [14]. Murine studies demonstrate that the latent genes of MHV-68 induce lung fibrosis in mice via TGF- $\beta$, vascular endothelial growth factor, CCL2, CCL12, TNF- $\alpha$ and IFN- $\gamma$ [15]. EBV lytic gene expression also activates TGF- $\beta$ expression in alveolar epithelial cell lines [16] and in primary corneal epithelial cells [17] where EBV can induce epithelial-mesenchymal transition (EMT) [18]. Moreover, the fibrotic cytokine milieu in IPF lung may activate virus replication and further promote virus gene expression in fibrotic lung. TGF- $\beta$ promotes EBV reactivation from latency to the lytic replication stage and further induces latent membrane protein expression, which synergizes with TGF- $\beta 1$ to induce EMT in lung epithelial cells [19]. Given these mechanisms, it is reasonable to speculate that viruses may play a role in the pathogenesis of IPF.

If viruses are responsible for causing IPF, then viral screening or anti-viral treatment may provide a diagnostic test or a potential treatment. Previously employed techniques, including immunohistochemistry, fluorescence in situ hybridization (FISH), gene array and PCR, are not sufficiently sensitive or specific. Thus, a more sensitive and reliable technique is required to qualify and quantity viruses at the DNA, or RNA levels. Nextgeneration sequencing offers high sensitivity, specificity and reproducibility in the detection of low levels of gene expression as well as a broad dynamic range afforded by the high sequencing depth. New high throughput technologies have been used to generate comprehensive sequencing data for the identification and quantification of known and novel genes in several diseases [20]. Moreover, RNA-seq has the potential to further elucidate the mechanisms of pathogenesis of IPF by identifying novel viruses not previously implicated by PCR or array based methods. Here we have utilized RNA-seq for the detection of virus expression in lung tissue from patients with IPF and their age-matched controls.

\section{Methods}

\section{Sample description}

Lung tissue samples for the first group were obtained from remnants of surgical biopsies from the University of Alabama at Birmingham (UAB) according to IRB (approval number N120410001 and 12-334398E). They included 5 control lungs and 12 IPF lungs. The control lung samples were obtained from histological diseasefree margins from patients undergoing resection of lung adenocarcinoma. The diagnosis of IPF patients was made by clinicians, pathologists and radiologists according to diagnostic criteria of the American Thoracic Society and the European Respiratory Society [21]. The detailed demographics for the first group are available at GEO along with raw RNA-seq data (accession numbers: GSE138239 for poly(A) selected RNA-seq data and GSE138283 for non-poly(A) selected RNA-seq data). The demographics and description for lung tissue samples for the second and third groups were previously published [22-24]. IPF patients for the second group of samples (Pittsburgh) and the third group of samples (FFPE) were vetted using the 2000 and 2011 ATS/ERS guidelines respectively $[21,25]$.

\section{RNA-sequencing data acquisition from IPF and control lung}

For this report, we analyzed RNA expression from 3 groups that in total were derived from $28 \mathrm{IPF}$ and 20 control lung specimens. The first group included samples from 12 IPF patients and 5 controls, and encompassed patients who underwent lung biopsies at the University of Alabama at Birmingham. Total RNA was prepared using Qiagen's RNeasy kit (cat\#74104). Poly(A) selected RNA-sequencing (RNA-seq) was performed at $\mathrm{UAB}$ for the first group (one control (3007) and one IPF (2053) sample was not analyzed by RNA-seq because the aliquot of RNA was considered to be of insufficient quality for these two samples). We repeated RNAsequencing on this same group at Tulane, but we did not select for polyadenylation because some viral genes are not polyadenylated. Non-poly(A) selected RNA-seq was performed using the Illumina NextSeq 550 located within the NextGen Sequencing Core at the Tulane Center for Translational Research in Infection \& Inflammation. Ribosomal RNA was removed from $1 \mu \mathrm{g}$ total RNA for both poly(A) selected and non-poly(A) selected RNA-seq, and a library was prepared using TruSeq stranded mRNA (polyA+) for poly(A) selected RNA-seq or using TruSeq stranded total RNA ribozero [12] for non-poly(A) selected RNA-seq from Illumina. The second group, including 10 IPF samples and 10 agematched controls, were from a poly(A) selected RNAseq dataset provided from the University of Pittsburg. The lung tissue for the Pittsburg group was part of the LTRC (Lung Tissue Research Consortium) specimen bank that was funded by NHLBI biospecimen repository. The third group, including 6 IPF lungs and 5 controls, was obtained from a RNA-seq dataset downloaded from 
the sequence read archive (SRA, PRJNA326784, https:// www.ncbi.nlm.nih.gov/sra?linkname=bioproject_sra all\&from_uid=326784), and was generated with nonpoly(A) selected total RNA [24]. RNA from the third group was isolated from paraffin-embedded tissue. Although we acknowledge that fixation in group 3 had the potential to damage nucleic acids, RNA-seq for these samples was considered reliable based on the original report ( $\sim 62$ million mapped reads in 116 million reads at 50 bp per sample) [24].

\section{Virome analysis of the RNA-sequencing data}

Raw RNA-seq data was aligned to a genome reference containing the human genome (hg19; genome reference consortium GRCh37) plus a library of 740 known mammalian viral sequences that have been documented by the NCBI (National Center for Biotechnology Information). Alignments were performed using the transcript aligner STAR (Spliced Transcripts Alignment to a Reference) version 2.3.0 and version 2.5.2a. Uniquely mapped viral and human reads were quantified using in-house computational pipelines. The first script extracts all the reads mapping to virus sequences and writes the output to one file for each sample. The second script takes as input all the viral sequence information from the first script and removes any duplicate reads. The output is a list of all the uniquely mapped viral sequences for each sample. The third script takes as input the uniquely mapped reads for each sample and counts the number of reads mapping to each virus in each sample. The output is a compiled file that contains the virus chromosome name followed by the number of occurrences in each aligned file. As a complementary approach, we also analyzed mapped reads using the metatranscriptomics pipeline, RNA CoMPASS for entire metatranscriptome analysis [26].

\section{CDNA synthesis and RT-PCR}

cDNA was synthesized with $1 \mu \mathrm{g}$ RNA following the manufacturer's instructions within the Bio-Rad iScrip ${ }^{\text {tm }}$ cDNA Synthesis Kit (cat\#170-8891). PCR was performed with $2 \mu \mathrm{l}$ of $10 \mathrm{X}$ diluted cDNA in a $20 \mu \mathrm{l}$ volume according to the manufacturer's protocol (BioRAD cat\#170-8880). PCR conditions: for EBV we used 3 min at $95^{\circ} \mathrm{C}, 40$ cycles of $15 \mathrm{~s}$ at $95^{\circ} \mathrm{C}$ and $30 \mathrm{~s}$ at $60^{\circ} \mathrm{C}$ then $40 \mathrm{~s}$ at $72^{\circ} \mathrm{C}$ [27]; to detect $\mathrm{HCV}$, we followed the methods of Lin et al. [28]; to detect HHV-7, we followed Caserta's method [29]; to detect saimiri expression, we followed Folcik 's method [30] using the primers listed on Table 1. HERV-K strand-specific nested-RT-PCR products from primers designed to detect RNAs spliced at the conventional envelope (env) mRNA splice junction (sense strand, $1 \times$-env) following the nested-PCR and quantitative RT-PCR protocol of Agoni et al. [32]. In brief, $1 \mathrm{x}$-env products were amplified with cDNA reverse transcript using primers for RT-env-1-Rev then nested-PCR with primers env (1) \& [31]. The primer sequences used for RT-PCR analysis were listed in Table 1. Relative transcript expression levels were calculated using the $\Delta \Delta \mathrm{Ct}$ method and the fold change of relative transcript expression was calculated by $\Delta \Delta \mathrm{Ct}$ of IPF/ $\Delta \Delta \mathrm{Ct}$ of control (CNTL).

\section{Statistical analyses}

RT-PCR was performed in triplicate for each sample. In order to test the significant difference of RT-PCR data and/or RNA-seq reads (RPHM), we used student's ttests and $\mathrm{F}$ tests that were performed using GraphPad

Table 1 Nucleotide sequence of primer sets used for RT-PCR analysis in this study

\begin{tabular}{|c|c|c|c|}
\hline Genes & & Forward nucleotide sequence $\left(5^{\prime} \rightarrow 3^{\prime}\right)$ & Revers nucleotide sequence $\left(5^{\prime} \rightarrow 3^{\prime}\right)$ \\
\hline EBV EBERs & & GACTCTGCTTTCTGCCGTCT & AATAGCGGACAAGCCGAATA \\
\hline \multirow[t]{6}{*}{ HERV-K } & RT-env-1-Rev & & CACCGCACTATTGGCCACA \\
\hline & Nested-PCR env(1) & AGGGAAAAACCGCCTTAGGG & CACCGCACTATTGGCCACA \\
\hline & Nested-PCR env [31] & TGCGGGCAGCAATACTGCT & CGCACTATTGGCCACACATTC \\
\hline & Quantitative PCR env & TCACATGGTAAGCGGGATGTC & CGCACTATTGGCCACACATTC \\
\hline & Quantitative PCR LTR & AGGGAAAAACCGCCTTAGGG & AGCAGACAAACATGTGAACAAAGG \\
\hline & LTR-Fwd |-Rev & CGTGGGAAGGGAAAGACCTGA & AGCAGACAAACATGTGAACAAAGG \\
\hline GAPDH & GAPDH & AGATCATCAGCAATGCCTCCT & AGTCTTCTGGGTGGCAGTG \\
\hline \multirow[t]{2}{*}{$\mathrm{HCV}$} & p3804|p305 & GTATCTCGAGGCGACACTCCACCATAGAT & ATACTCGAGGTGCACGGTCTACGAGACCT \\
\hline & p302|p304 & CCACCATAGATCTCTCCCCTGT & CACTCTCGAGCACCCTATCAGGCAGT \\
\hline \multirow[t]{2}{*}{ Saimiri virus } & Human cyclin D1 & CGGAGGAGAACAAACAGATCATCCGCAAAC & GTGTGAGGCGGTAGTAGGACAGGAAGTTGT \\
\hline & Viral cyclin D1 & ACTGCTTACCTGGATGCATCTGCTCTGTGA & GCAAGTACAGCTTCAGTGTGTCCCATTTCAGTGC \\
\hline \multirow[t]{2}{*}{$\mathrm{HHV}-7$} & $\mathrm{G} 1 \mid \mathrm{G} 2$ & CATGCACAACGCAAGCTCTACTA & ACGTAGTTTCGTGCAGTTGTATCGT \\
\hline & $\mathrm{G} 3 \mid \mathrm{G} 4$ & GCTTGTTAGAATACACAAGATGTACA & CTGTCTAATAATGTCTATGTCTCTCCA \\
\hline
\end{tabular}


Prism. T-tests were used to compare differences between control and IPF groups, and the F tests were employed to compare variance within the groups (control group or IPF group). Differential expression analysis of RNA-Seq was carried out using the EBSeq statistical package. Scatter plots depict the mean with the standard error of the mean [33]. Statistical significance was defined at an alpha value of $p<0.05$. Results are expressed as mean \pm SEM.

\section{Results}

\section{Quantitation of viral gene expression using RNA- sequencing}

Although we observed that the Shamonda virus averages 10 reads per million human mapped reads (RPHM) in poly(A) selected RNA-seq, this is likely an artifact and not true infection because viral reads were detected in every sample analyzed, including the normal controls. In addition, manual BLAST showed that the actual reads hit to human sequences that were mistakenly being called Shamonda virus, and a few repeat reads have been clonally amplified and resulting in such a high read number. The next most commonly detected virus was human adenovirus $\mathrm{C}$ with 1 read per million human mapped reads (Table 2). The mapped reads of other viruses were very low (under 1 RPHM, Table 2) in poly(A) selected RNA-seq. This could be due to exclusion of viral RNA that is not polyadenylated. To detect viral encoded non-coding RNAs, we performed a non-poly(A) RNA-seq using ribodepleted RNA libraries for our initial group 1 samples (5 controls and 12 IPF lungs). Nonpoly(A) selected RNA-seq detected more virus than poly(A) selected RNA-seq, including tick-born encephalitis virus, herpesvirus 2 (HHV-2, HSV-2), Roseolovirus (HHV-6B) and EBV (HHV-4, Table 3, Table S3). However, there were no significant differences between control and IPF (Table 3, Tables S3, S4). These data were confirmed by analysis of viral RNA expression using another non-poly(A) selected RNA-seq datasets (the third group dataset, Table S5). Overall, none of the samples from either the control or IPF groups reached a virus detection threshold high enough to qualify as positive. We conclude that there are no viruses associated with IPF tissue samples (Table 2, Table S1).

\section{Screening for EBV, HCV, HHV-7 and herpesvirus saimiri RNA using real-time RT-qPCR}

To confirm our RNA-seq results, we performed serial RT-qPCR on the first group of specimens (12 IPF and 5 control lung RNAs). This was not performed on the second and third group because we only had the data sets and not the RNA. EBV has two major infection gene expression programs, the latency associated gene expression program and the lytic gene expression program, which are uniquely utilized depending on cell type. Since it is not known which cell type might harbor EBV within IPF lung, and to avoid "lack of detection" errors due to EBV infection status, primers spanning the EBV latent genes, EBNA1, Qp and LMP1, as well as the EBV lytic gene Zta were employed for RT-qPCR. No EBV latent or lytic gene expression was detected using RT-qPCR, suggesting that neither the latent nor the lytic forms of EBV were present in the lungs of IPF patients or the control group (data not shown). However, using primers that span the EBV-encoded noncoding small RNAs, EBER1 to EBER2, we detected a very low level of EBERs expression in both the IPF and control specimens, with cycle threshold [34] values over 33 cycles and with no significant difference between the two groups (Fig. 1a). This data is consistent with the analysis of the non-polyA selected RNA-seq.

Other ubiquitous herpes viruses have also been reported to be associated with IPF, including herpes simplex virus type 1 (HSV-1), HHV-6, -7 and -8 and cytomegalovirus (CMV) [2]. Our RNA-seq data detected sporadic and very low virus mapped reads per million human mapped reads (RPHM - reads per million human mapped) for these viruses; HHV-5 with 1 RPHM in IPF lung and 2 RPHM in control lung; HHV-6 with 1 RPHM read in control and HHV-7 with 2 RPHM in IPF (Table 2). RT-qPCR Ct values for these viruses were around 40 , and therefore not reliable for quantification of these HHVs (data not shown). Chronic infection of $\mathrm{HCV}$ has been implicated in liver fibrosis; however, it is still debatable whether HCV can cause pulmonary fibrosis. While some research indicates that $\mathrm{HCV}$ infection may play an important role in the pathogenesis of IPF $[4,5]$, others have not detected HCV RNA in IPF samples, despite detection in some specimens using ELISA $[10,35]$. No HCV mapped reads were detected in any of our IPF or control lung specimens using RNA-seq (Table S1). A nested real-time RT-qPCR assay with primers spanning the 5-UTR of $\mathrm{HCV}[28,36]$ detected very low levels of $\mathrm{HCV}$ transcripts with $\mathrm{Ct}$ value over 30 cycles (Fig. 1b). Importantly, the $\Delta \Delta \mathrm{Ct}$ for $\mathrm{HCV}$ was not significantly different between IPF and controls (Fig. 1b).

More recently, Folcik et al. reported that IPF is associated with herpesvirus saimiri but not with other herpesviruses such as EBV, KSHV, CMV or HSV I/II [30]. They detected herpesvirus saimiri DNA and RNA in all 13 IPF cases and none of their controls. Herpesvirus saimiri is a member of the rhadinovirus genus, which also includes Kaposi's sarcoma-associated herpesvirus, and can infect humans and squirrel monkeys without causing disease. Around $4.0-7.3 \%$ of humans are seropositive and express viral proteins such as viral cyclin D [37]. Although no substantial herpesvirus saimiri virus reads were detected in any of the IPF and control specimens 
Table 2 Summary of the number of virus mapped reads per million human mapped reads (RPHM) for IPF and control lung specimens from first and second group in poly(A) selected RNA-seq and third group in non-poly(A) selected RNA-seq. Viruses were displayed here if at least one viral mapped read was detected in at least one sample. The total mapped reads of human are for quality control

\begin{tabular}{|c|c|c|c|c|c|c|c|c|}
\hline \multirow[t]{2}{*}{ Virus name } & \multicolumn{4}{|l|}{ Control } & \multicolumn{4}{|l|}{ IPF } \\
\hline & $\begin{array}{l}\text { \# of } \\
\text { samples }\end{array}$ & $\begin{array}{l}\% \text { of } \\
\text { samples }\end{array}$ & Min & Max & $\begin{array}{l}\text { \# of } \\
\text { samples }\end{array}$ & $\begin{array}{l}\% \text { of } \\
\text { samples }\end{array}$ & Min & Max \\
\hline \multicolumn{9}{|l|}{ 1st group } \\
\hline Human & 4 & $100 \%$ & $\begin{array}{l}26,511 \\
620\end{array}$ & $\begin{array}{l}39,945 \\
034\end{array}$ & 11 & $100 \%$ & $\begin{array}{l}23,500 \\
148\end{array}$ & $\begin{array}{l}44,071 \\
337\end{array}$ \\
\hline Cytomegalovirus & 0 & $0 \%$ & 0 & 0 & 1 & $9 \%$ & 0.80 & 0.80 \\
\hline Adenovirus C & 0 & $0 \%$ & 0 & 0 & 2 & $18 \%$ & 0.03 & 0.07 \\
\hline Mouse mammary tumor virus & 1 & $25 \%$ & 0.03 & 0.03 & 4 & $36 \%$ & 0.03 & 0.05 \\
\hline Simbu virus & 3 & $75 \%$ & 0.03 & 0.23 & 5 & $45 \%$ & 0.03 & 0.20 \\
\hline Immunodeficiency virus 1 & 0 & $0 \%$ & 0 & 0 & 1 & $9 \%$ & 0.03 & 0.03 \\
\hline Hepatitis C virus genotype 1 & 0 & $0 \%$ & 0 & 0 & 1 & $9 \%$ & 0.03 & 0.03 \\
\hline Hepatitis C virus genotype 2 & 0 & $0 \%$ & 0 & 0 & 1 & $9 \%$ & 0.04 & 0.04 \\
\hline Papillomavirus 110 & 0 & $0 \%$ & 0 & 0 & 1 & $9 \%$ & 0.02 & 0.02 \\
\hline Shamonda virus & 4 & $100 \%$ & 5.407 & 15.489 & 11 & $100 \%$ & 0.03 & 15.98 \\
\hline \multicolumn{9}{|l|}{ 2nd group } \\
\hline Human & 10 & $100 \%$ & $\begin{array}{l}19,847 \\
360\end{array}$ & $\begin{array}{l}37,420 \\
687\end{array}$ & 10 & $100 \%$ & $\begin{array}{l}21,826 \\
038\end{array}$ & $\begin{array}{l}41,977 \\
536\end{array}$ \\
\hline Cytomegalovirus & 0 & $0 \%$ & 0.00 & 0.00 & 2 & $20 \%$ & 0.07 & 0.14 \\
\hline Herpesvirus 6A & 0 & $0 \%$ & 0.00 & 0.00 & 1 & $10 \%$ & 0.04 & 0.04 \\
\hline Herpesvirus 7 & 2 & $20 \%$ & 0.03 & 0.04 & 0 & $0 \%$ & 0 & 0 \\
\hline Adenovirus C & 10 & $100 \%$ & 0.05 & 0.35 & 10 & $100 \%$ & 0.05 & 1.05 \\
\hline Simian virus 40 & 1 & $10 \%$ & 0.03 & 0.03 & 0 & $0 \%$ & 0 & 0 \\
\hline Papillomavirus 16 & 1 & $10 \%$ & 0.04 & 0.04 & 0 & $0 \%$ & 0 & 0 \\
\hline Shamonda virus & 10 & $100 \%$ & 0.35 & 6.28 & 10 & $100 \%$ & 1.42 & 11.17 \\
\hline \multicolumn{9}{|c|}{ 3rd group } \\
\hline Tick-borne encephalitis virus & 2 & $40 \%$ & 0.00 & 0.11 & 2 & $33 \%$ & 0.00 & 0.06 \\
\hline Hepatitis C virus genotype 1 & 5 & $100 \%$ & 0.03 & 3.63 & 6 & $100 \%$ & 0.14 & 1.07 \\
\hline Hepatitis C virus genotype 6 & 3 & $60 \%$ & 0.00 & 0.04 & 2 & $33 \%$ & 0.00 & 0.03 \\
\hline Hepatitis C virus genotype 2 & 4 & $80 \%$ & 0.00 & 0.11 & 5 & $83 \%$ & 0.00 & 0.09 \\
\hline Adenovirus C & 5 & $100 \%$ & 0.02 & 0.33 & 6 & $100 \%$ & 0.78 & 3.27 \\
\hline Adenovirus E & 0 & $0 \%$ & 0.00 & 0.00 & 1 & $17 \%$ & 0.00 & 0.03 \\
\hline Herpesvirus 1 & 0 & $0 \%$ & 0.00 & 0.35 & 1 & $17 \%$ & 0.00 & 0.06 \\
\hline Herpesvirus 2 & 1 & $20 \%$ & 0.00 & 0.04 & 5 & $83 \%$ & 0.00 & 0.03 \\
\hline Epstein-Bar virus & 1 & $20 \%$ & 0.00 & 0.04 & 1 & $17 \%$ & 0.00 & 0.14 \\
\hline Cytomegalovirus & 4 & $80 \%$ & 0.00 & 0.41 & 2 & $33 \%$ & 0.00 & 0.09 \\
\hline Herpesvirus 7 & 3 & $60 \%$ & 0.00 & 0.07 & 0 & $0 \%$ & 0.00 & 0.00 \\
\hline $\begin{array}{l}\text { Kaposi's sarcoma-associated } \\
\text { herpesvirus }\end{array}$ & 1 & $20 \%$ & 0.00 & 0.02 & 1 & $17 \%$ & 0.00 & 0.02 \\
\hline Cutthroat trout virus & 0 & $0 \%$ & 0.00 & 0.00 & 3 & $50 \%$ & 0.00 & 0.03 \\
\hline Measles virus & 0 & $0 \%$ & 0.00 & 0.00 & 2 & $33 \%$ & 0.00 & 0.03 \\
\hline Abelson murine leukemia virus & 5 & $100 \%$ & 0.01 & 0.31 & 1 & $17 \%$ & 0.00 & 0.03 \\
\hline Shamonda virus & 3 & $60 \%$ & 0.00 & 0.05 & 1 & $17 \%$ & 0.00 & 0.03 \\
\hline Simian virus 40 & 5 & $100 \%$ & 0.02 & 0.46 & 5 & $83 \%$ & 0.00 & 0.06 \\
\hline
\end{tabular}


Table 2 Summary of the number of virus mapped reads per million human mapped reads (RPHM) for IPF and control lung specimens from first and second group in poly(A) selected RNA-seq and third group in non-poly(A) selected RNA-seq. Viruses were displayed here if at least one viral mapped read was detected in at least one sample. The total mapped reads of human are for quality control (Continued)

\begin{tabular}{|c|c|c|c|c|c|c|c|c|}
\hline \multirow[t]{2}{*}{ Virus name } & \multicolumn{4}{|l|}{ Control } & \multicolumn{4}{|l|}{ IPF } \\
\hline & $\begin{array}{l}\text { \# of } \\
\text { samples }\end{array}$ & $\begin{array}{l}\% \text { of } \\
\text { samples }\end{array}$ & Min & Max & $\begin{array}{l}\text { \# of } \\
\text { samples }\end{array}$ & $\begin{array}{l}\% \text { of } \\
\text { samples }\end{array}$ & Min & Max \\
\hline Papillomavirus 28 & 0 & $0 \%$ & 0.00 & 0.00 & 1 & $17 \%$ & 0.00 & 0.03 \\
\hline Papillomavirus 100 & 0 & $0 \%$ & 0.00 & 0.00 & 1 & $17 \%$ & 0.00 & 0.03 \\
\hline
\end{tabular}

using RNA-seq (Table 2 \& S1), we still performed RTqPCR to assess expression of herpesvirus saimiri using primers against viral cyclin D1 and viral ORF73 (a conserved viral gene). We did not detect significant expression of ORF73 in IPF patient samples compared to controls (data not shown). We observed high expression of human cyclin D1 (Fig. 2b) and very low expression of viral cyclin D1 (Ct value over 30, Fig. 2a) in both IPF and control samples, indicating lack of an association between herpesvirus saimiri and IPF.

Table 3 Comparison of the virome reads between non-poly(A) selected RNA-seq (non-poly(A)) with poly(A) selected RNA-seq (poly(A)) from first group of lung tissue. The numbers correspond to the average virome reads per million human mapped reads

\begin{tabular}{|c|c|c|c|c|}
\hline \multirow[t]{2}{*}{ Viruses } & \multicolumn{2}{|c|}{ Non-poly(A) } & \multicolumn{2}{|l|}{ Poly(A) } \\
\hline & Controls & $\mathrm{IPF}$ & Controls & IPF \\
\hline Cytomegalovirus & 0.15 & 0.18 & 0.00 & 0.80 \\
\hline Hepatitis C virus genotype 2 & 2.05 & 2.57 & 0.00 & 0.04 \\
\hline Hepatitis C virus genotype 6 & 0.49 & 0.61 & 0.00 & 0.00 \\
\hline Hepatitis C virus genotype 1 & 0.15 & 0.16 & 0.00 & 0.03 \\
\hline Tick-borne encephalitis virus & 0.23 & 0.22 & 0.00 & 0.00 \\
\hline Abelson murine leukemia virus & 0.09 & 0.14 & 0.06 & 0.05 \\
\hline Shamonda virus & 0.08 & 0.09 & 9.15 & 3.52 \\
\hline Cutthroat trout virus & 0.02 & 0.02 & 0.00 & 0.00 \\
\hline Murine type $C$ retrovirus & 0.02 & 0.01 & 0.00 & 0.00 \\
\hline Simbu virus & 0.02 & 0.02 & 0.10 & 0.08 \\
\hline Moloney murine leukemia virus & 0.02 & 0.00 & 0.03 & 0.02 \\
\hline Herpesvirus 2 & 0.01 & 0.01 & 0.00 & 0.00 \\
\hline Epstein-barr virus & 0.01 & 0.01 & 0.00 & 0.00 \\
\hline Herpesvirus 6B & 0.01 & 0.00 & 0.00 & 0.00 \\
\hline Adenovirus C & 0.00 & 0.00 & 0.00 & 0.05 \\
\hline Immunodeficiency virus 1 & 0.00 & 0.00 & 0.00 & 0.03 \\
\hline Papillomavirus 110 & 0.00 & 0.00 & 0.00 & 0.02 \\
\hline Mouse mammary tumor virus & 0.00 & 0.00 & 0.03 & 0.03 \\
\hline HERV-K & 96.35 & 94.04 & 29.36 & 52.11 \\
\hline HERV-W & 4.58 & 4.00 & 0.21 & 0.44 \\
\hline HERVs & 102.80 & 99.41 & 32.87 & 54.39 \\
\hline
\end{tabular}

HERV-K gene expression and coverage in IPF patients HERV sequences make up about $4.9 \%$ of the human genome. HERV-K research has been assessed in autoimmune disorders and oncogenesis, yet to date we are not aware of any literature to assess its possible role in pulmonary fibrosis. Recently, RT-PCR results have suggested that HERV-K env mRNA was increased in PBMC and skin biopsies of morphea/localized scleroderma [38]. This study suggests that HERV-K env may be functionally linked to fibrosis. HERV-K gene expression could theoretically promote IPF through cell stress, and HERV-K expression is reported to be higher with EBV infection [39]. Therefore, we evaluated whether HERV-K genes are upregulated in IPF lung. Notably, of the viruses analyzed in poly(A) selected RNA-seq, HERV-K was the virus with the highest read numbers (23 to 83 HERV-K mapped reads per million human mapped reads in both IPF and control samples) (Fig. 3a \& Table S2). Statistical analysis showed about a 2-fold increase in the 11 IPF patient samples compared 5 controls in group 1 (Fig. 3a \& b). However, no statistical difference was evident between IPF and controls in the second group (Fig. 3a \& b). These data were confirmed by non-poly(A) selected RNA-seq in the initial group and the third group. Non-poly(A) selected RNA-seq detected more HERV mapped reads than poly(A) selected RNA-seq (Table 3, Table S4, Table S5). Overall we were not able to make an association between HERV-K gene expression and IPF.

Quantitative RT-PCR of the HERV-K env and long terminal repeat (LTR) regions show that the expression levels of env and LTR were higher in IPF than in controls (two-fold difference, Fig. 3d), which corroborates the RNA-seq data. Next, strand-specific nested RT-PCR was performed with primers spanning the HERV-K env and LTR regions in group 1 . The primers were originally designed to detect viral $1 \mathrm{x}$ env splicing transcripts [32]. Since HERV-K can be transcribed from the LTR at either or both directions, the sense strand and anti-sense strand, we performed strand-specific RT-PCR to detect the plus strand and the minus strand using forward (LTR-Fwd) or reverse primers (LTR-Rev) for reverse strand transcription of the LTR. As shown in Fig. 3c, we found no statistical difference in expression of env and 
A.
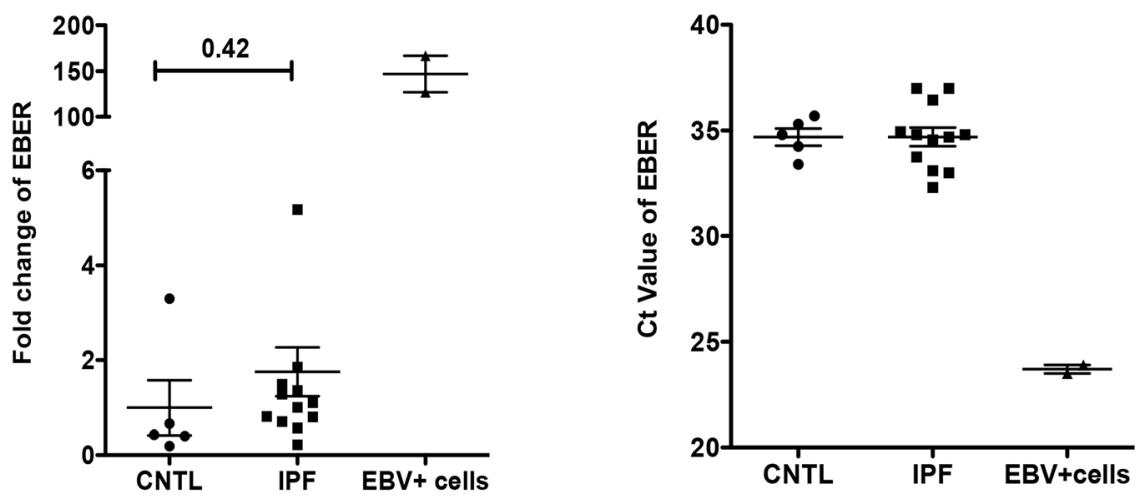

B.
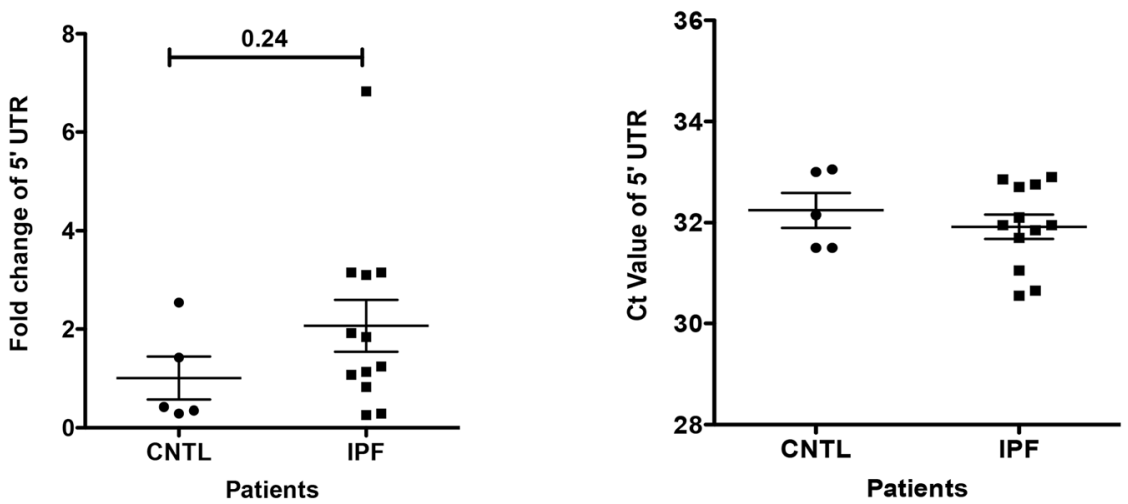

Fig. 1 Evaluation of EBV and HCV expression levels in IPF and control lung specimens by RT-qPCR. a To evaluate EBV expression levels, RT-qPCR was performed using primers against EBER. $\mathbf{b}$ HCV expression was assessed using primers against the 5'UTR

LTR from either direction between IPF and controls. We observed that there were several different sizes of env spliced transcripts. Eleven of 12 (91.7\%) IPF samples were env positive, compared to 3 of $5(60 \%)$ controls, and the majority of env transcripts were large in IPF (9 of 11), compared with 1 of 3 env in controls (Fig. 3c). In summary, the spliced env appears preferentially expressed in IPF, and we do not yet know whether the large env may play a role in IPF pathogenesis.

\section{Discussion}

Here we used RNA-seq to characterize 740 virus gene expression profiles in 28 IPF biopsies and 20 agematched controls. RNA-seq did not provide evidence for an association between any virus and IPF. Studies using RT-PCR for HERV-K, saimiri, EBV, HHV7 and HCV by RT-PCR corroborated the RNA-seq results. Our findings provide a new scope for exploring the causes of IPF by using the sensitive RNA-seq method.

To enable us to analyze both viral poly(A) and nonpoly(A) mRNA in the same sample, we divided total RNA extracted from surgical lung biopsies into a poly(A) enriched fraction via oligo ( $\mathrm{dT}$ ) for poly(A)-selected RNA-seq, and a non-poly(A) fraction for non-poly(A)selected RNA-seq. Similar to eukaryotic mRNAs, viral mRNAs have two main types: poly(A) and non-poly(A) transcripts, based on the presence or absence of a poly(A) tail at their 3'-end. Poly(A) mRNA transcripts represent the majority of viral mRNA, however some viruses express non-poly(A) mRNA including miRNA and lncRNA. Important examples are herpesvirus EBVencoded non-coding small RNAs (EBER), and adenovirus-encoded non-coding RNA VA (viral associated) RNAs. Viral-encoded non-poly(A) RNAs have an essential role in a variety of physiological conditions and in several illnesses, including viral life cycle and function, host cell immune evasion and transformation [40]. Specifically, EBERs are highly abundant in all latently EBVinfected cells and play a significant role in the pathogenesis of EBV infection including contributions to EBVmediated oncogenesis such as Burkitt's lymphoma, gastric carcinoma and nasopharyngeal carcinoma through regulation of apoptosis and/or several cytokines [41]. As such, EBERs are the gold standard clinic markers for 
A.
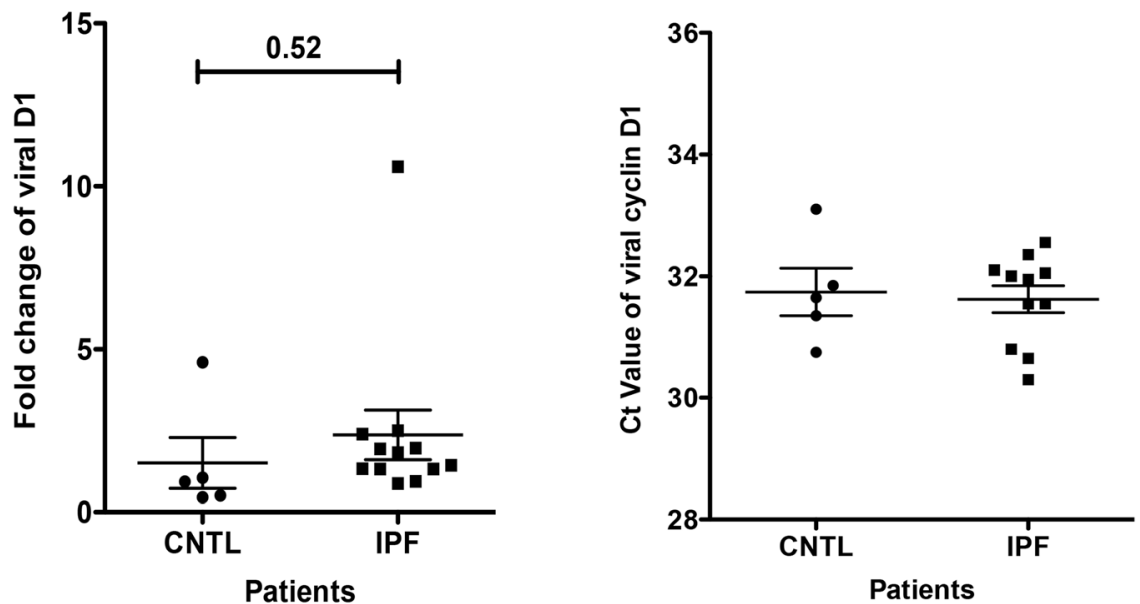

B.
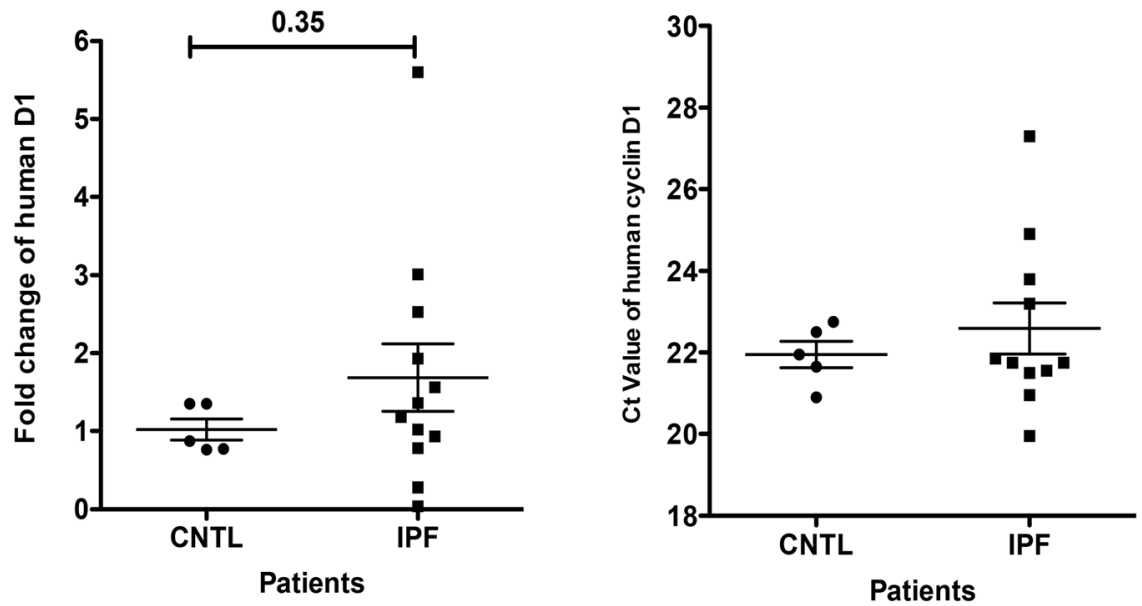

Fig. 2 Detection of herpesvirus saimiri expression in IPF and control lung specimens. a Saimiri virus was assessed using RT-qPCR using primers designed for viral cyclin D1. b Human cyclin D1 was evaluated using RT-qPCR using primers designed for human cyclin D1

detection of EBV latent infection in specimens. For this reason, we analyzed viral poly(A) and non-poly(A) mRNAs separately on the same sample from the first group.

EBV appears to be the most commonly investigated virus in IPF. Previous research has suggested that IPF is linked to EBV, while other studies, using some common techniques such as PCR with primers from the EBV BamHI W repeats or the EBER gene, FISH with an EBER probe, and IHC with antibody against the viral capsid antigen (VCA) or the latent membrane protein 1, have found no link [9]. Here, we did not detect EBV latent or lytic gene expression differences using RNA-seq or real-time RT-qPCR between the lungs of IPF patients compared to control lungs. Nevertheless, we detected very low level of EBER in both IPF and control lung with no difference between the two groups, and this is not unexpected since most people are latently infected with EBV. Notably, EBV EBERs are the most highly expressed EBV latent genes, typically with greater than 1 million RNA molecules per cell [42]. EBERs were detected at very low-levels in the non-poly(A) selected RNA-seq dataset (Table S3) and in real-time RT-qPCR, but not in poly(A) selected RNA-seq. Their quantification failed to demonstrate enhancement of EBV gene expression in IPF specimens, thus implying that the EBV virus is not associated with IPF lung any more than with normal lung.

HERV-K expression was examined because some reports have indicated that it is elevated in other fibrotic diseases and because conceptually HERV-K could promote fibrogenesis by inducing cellular stress. Moreover, 


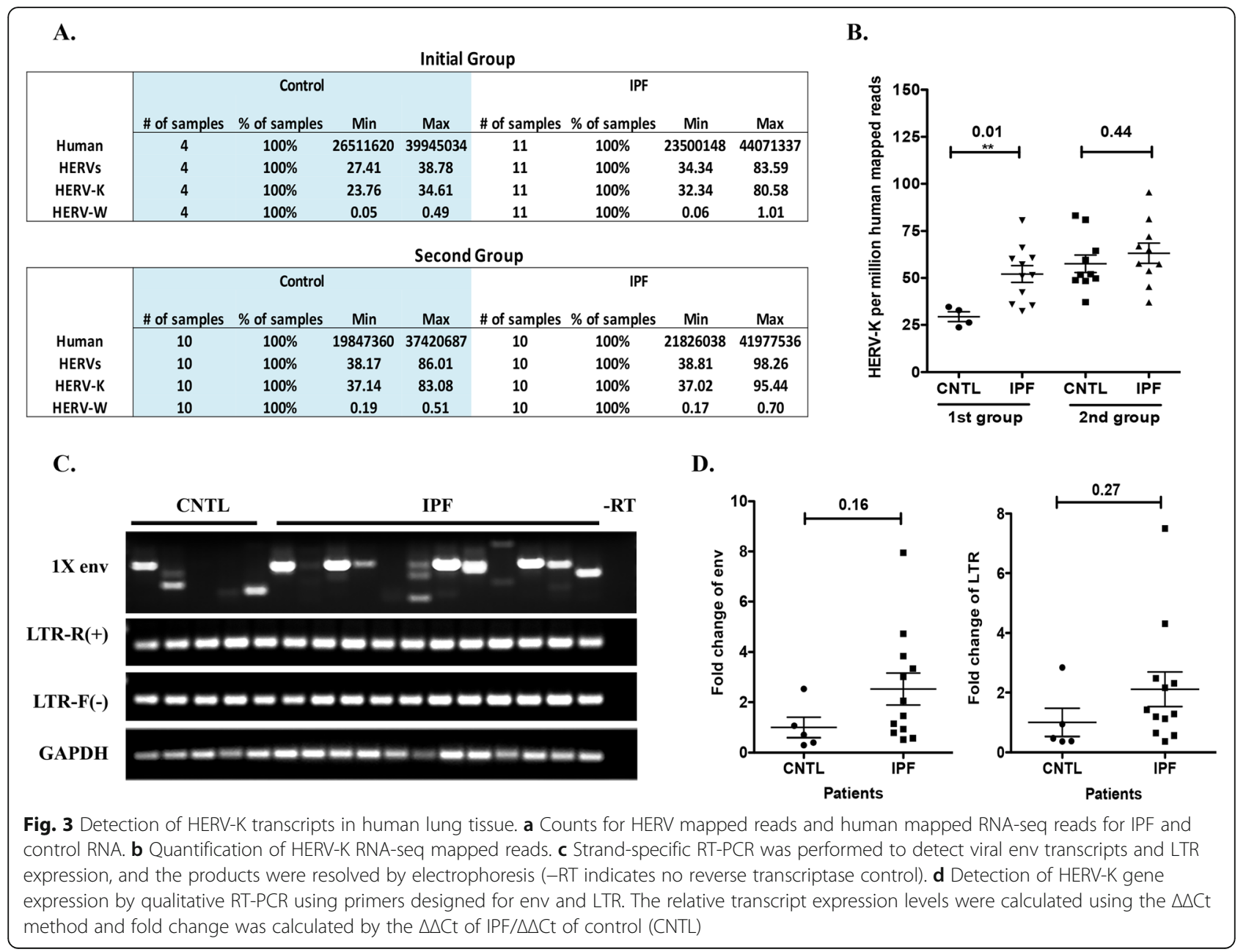

HERV-K expression is reportedly enhanced in response to herpes virus infection. HERV-K protein NP9 can negatively regulate EBV EBNA2 expression by binding to EBNA2 [43]. The env-encoded superantigens SAg and NP9 were increased in EBV-transformed lymphocytes, and further studies have demonstrated that the EBV genes LMP2A and LMP1 transactivate HERV-K gene expression $[44,45]$. Given the reported association between EBV and HERV-K, we hypothesized that gene expression of EBV and HERV-K should have a positive correlation. As such, we performed RT-PCR for HERV$K$ and EBV, and found expression of HERV-K env and LTR, but no or low expression of EBV (Fig. 2 and Fig. 1a). The absence of differences in overall HERV-K expression between IPF and control data further supports the concept that there is no association between EBV and IPF.

Although RNA-seq is highly sensitive technique to detect virus, there are still some limitations in our study. Most of the mapped viral reads detected in our study were low except for HERVs, and this potentially could be due to the quality of RNA-seq or the script used in our research. Additionally, the expression of RNA viruses is difficult to differentiate from genome detection despite the fact that viral RNA may indeed reveal expression of DNA viruses such as herpes. For persistent DNA viruses with very limited expression such as HBV, a strategy restricted to the detection of RNA such as RNA-seq, may miss these viruses. Finally, although a greater number of tissue samples would add to the confidence of our findings, we suggest the lack of significant findings in 28 IPF lungs from 3 different sources is compelling. Although our sample size makes it very unlikely to have missed a significant difference in expression of viral gene expression in common viruses, such as EBV, we are not able to fully exclude that there may be a small percentage of patients with IPF, or a specific IPF phenotype, that have expression viral RNA in lung.

This study has bearing as clinical investigators are considering anti-herpesvirus therapy as a treatment for IPF. A similar scenario existed for glioblastoma multiforme (GBM) in which, based on IHC, in situ hybridization, western blotting and RT-PCR, CMV was entertained as a causative factor for this fatal disease [46]. A clinical 
trial using anti-viral therapy to treat GBM was not effective [47]. Only after conclusion of the trial did next generation sequencing data come to light that refuted the role of CMV in GBM [48]. Our data indicates that a clinical trial employing anti-herpesvirus medication for the treatment of IPF would be unwarranted, with the caveat that it does not address so called acute exacerbations of IPF.

\section{Conclusions}

Our study employs next generation RNA-sequencing to assess whether viral infections are linked to the pathogenesis of IPF for the first time. Although quantification of viral RNAs using RNA-seq in IPF lung specimens does not support the role of viral infection in acute exacerbations of IPF, however, this analysis patently did not support an association between virus detection especially herpes virus detection and IPF.

\section{Supplementary information}

Supplementary information accompanies this paper at https://doi.org/10. 1186/s12890-020-1114-1.

Additional file 1: Table S1. Counts for human and virus mapped RNAseq reads for IPF and control lung RNA. Virus data is shown if at least one read was detected in at least one sample.

Additional file 2: Table S2. Counts for human and HERV-K \& HERV-W mapped RNA-seq reads for IPF and control lung RNA. Virus-encoded genes are shown if at least one read was detected in at least one sample.

Additional file 3: Table S3. Counts for virus mapped non-poly(A) selected RNA-seq reads for IPF and control lung RNA.

Additional file 4: Table S4. Counts for HERV mapped non-poly(A) selected RNA-seq reads for IPF and control lung RNA.

Additional file 5: Table S5. Counts for virus mapped SRA RNA-seq reads for IPF and control lung RNA.

\footnotetext{
Abbreviations

CCL12: Chemokine (C-C motif) ligand 12; CCL2: Chemokine (C-C motif) ligand 2; CMV: Cytomegalovirus; EBER: Epstein-Barr virus-encoded small RNA; EBNA: Epstein-Barr nuclear antigen; EBV: Epstein-Barr virus; ELISA: Enzymelinked immunosorbent assay; EMT: Epithelial-mesenchymal transition; env: Viral envelope; ER: Endoplasmic reticulum; FISH: Fluorescence in situ hybridization; GAPDH: Glyceraldehyde 3-phosphate dehydrogenase; GBM: Glioblastoma multiforme; HCMV: Human cytomegalovirus or human betaherpesvirus 5; HCV: Hepatitis C; HERV-E: Human endogenous retrovirus E; HERV-K: Human endogenous retrovirus K; HHV-2: Herpesvirus 2; HHV-6, -7 and -8 : Human herpesvirus-6, -7 and $-8 ; \mathrm{HHV}-6 \mathrm{~B}$ : Human betaherpesvirus 6B; HHVs: Human herpes viruses; HSV-1: Herpes simplex virus type 1; IFNY: Interferon gamma; IHC: Immunohistochemistry; IPF: Idiopathic pulmonary fibrosis; KSHV: Kaposi's sarcoma-associated herpesvirus; LMP1: Epstein-Barr latent membrane protein 1; LTR: Long terminal repeat; LTRC: Lung tissue research consortium; ORF: Open reading frame; PBMC: Peripheral blood mononuclear cell; PERK: Protein kinase R (PKR)-like endoplasmic reticulum kinase; RPHM: Reads per million human mapped reads; RT-PCR: Reverse transcription polymerase chain reaction; RT-qPCR: Quantitative reverse transcription PCR; SRA: Sequence read archive; TGF- $\beta$ : Transforming growth factor beta; TNF-a: Tumor necrosis factor alpha; TTV: Transfusion transmitted virus; UPR: Unfolded protein response; UTR: Untranslated region; VCA: Viral capsid antigen
}

\section{Acknowledgements}

We acknowledge Melody C. Baddoo with the Next Generation Sequence Analysis Core supported by the National Cancer Institute (P01CA214091) for virome analysis; Kejing Song and Cathy Flemington from the Tulane Center for Translational Research in Infection and Inflammation for performing nonpoly(A) selected RNA-seq, and Steven M. Rowe and Li Tang from University of Alabama at Birmingham for their technical support. This abstract was not presented at the PFF Summit 2019.

\section{Authors' contributions}

QY performed RNA-seq analysis, RT-PCR and participated in writing the manuscript. MS performed RNA-seq analysis for the first and second group data. YZ performed RNA extraction and RT-PCR for HERV-K. EKF assisted with RNA-seq analysis and edited the manuscript. NK provided the third group of raw RNA-seq data. JA provide IPF lung tissue samples. JL conceived of this study and participated in experimental design and analysis. He also co-wrote this manuscript. All authors read and approved the final manuscript.

\section{Funding}

This study was supported by the John Deming Endowed Chair for Research and the Wetmore Foundation [50] and Deep South Network for Translational Research Pilot Funding Selection Committee (JAL and J AdeA). These funding participated in the design of the study, collection, analysis, interpretation of data and writing of the manuscript.

\section{Availability of data and materials}

All data generated or analyzed during this study are included in this published article and its supplementary information files. Raw and processed RNA-seq data for the first group is available at Gene Expression Omnibus [49], accession numbers: GSE138239 for poly(A) selected RNA-seq data and GSE138283 for non-poly(A) selected RNA-seq data. The second and third group RNA-seq data have been previously uploaded to GEO and the lung genomics research consortium (www.lung-genomics.org) as shown in their publications $[22,23]$.

\section{Ethics approval and consent to participate}

The use of specimens was approved by the Tulane University Biomedical institutional review board (IRB, approval number 12-334398E), University of Alabama at Birmingham (approval number N120410001), University of Pittsburgh (approval number IRB0411036) and Yale School of Medicine (approval number 1409014689). Written informed consents were obtained as appropriate according to IRB.

\section{Consent for publication \\ Not applicable.}

\section{Competing interests}

The authors declare that they have no competing interests.

\section{Author details}

${ }^{1}$ Section of Pulmonary Diseases, Critical Care and Environmental Medicine, Department of Medicine, Tulane University School of Medicine, 1430 Tulane Avenue, New Orleans, LA 70112, USA. ${ }^{2}$ Department of Pathology and Laboratory Medicine, Tulane University School of Medicine, 1430 Tulane Avenue, New Orleans, LA 70112, USA. 3Section of Pulmonary, Critical Care and Sleep Medicine, Yale University, 300 Cedar Street, Ste S441D, New Haven, CT 06519, USA. Division of Allergy, Pulmonary, Critical Care Medicine, Department of Medicine, Vanderbilt University, 1161 21st Avenue South, B1317 MCN, Nashville, TN 37232-2650, USA.

Received: 16 July 2019 Accepted: 13 March 2020 Published online: 03 April 2020

\section{References}

1. Lederer DJ, Martinez FJ. Idiopathic pulmonary fibrosis. N Engl J Med. 2018; 378(19):1811-23.

2. Tang YW, Johnson JE, Browning PJ, Cruz-Gervis RA, Davis A, Graham BS, Brigham KL, Oates JA, Loyd JE, Stecenko AA. Herpesvirus DNA is consistently detected in lungs of patients with idiopathic pulmonary fibrosis. J Clin Microbiol. 2003;41(6):2633-40. 
3. Cheng G, Feng Z, He B. Herpes simplex virus 1 infection activates the endoplasmic reticulum resident kinase PERK and mediates elF-2alpha dephosphorylation by the gamma (1)34.5 protein. J Virol. 2005;79(3):137988.

4. Ueda T, Ohta K, Suzuki N, Yamaguchi M, Hirai K, Horiuchi T, Watanabe J, Miyamoto T, Ito K. Idiopathic pulmonary fibrosis and high prevalence of serum antibodies to hepatitis C virus. Am Rev Respir Dis. 1992;146(1):266-8.

5. Arase $Y$, Suzuki F, Suzuki $Y$, Akuta N, Kobayashi M, Kawamura $Y$, Yatsuji H, Sezaki H, Hosaka T, Hirakawa M, et al. Hepatitis C virus enhances incidence of idiopathic pulmonary fibrosis. World J Gastroenterol. 2008;14(38):5880-6.

6. Kuwano K, Nomoto Y, Kunitake R, Hagimoto N, Matsuba T, Nakanishi Y, Hara N. Detection of adenovirus E1A DNA in pulmonary fibrosis using nested polymerase chain reaction. Eur Respir J. 1997;10(7):1445-9.

7. Calabrese F, Kipar A, Lunardi F, Balestro E, Perissinotto E, Rossi E, Nannini N, Marulli G, Stewart JP, Rea F: Herpes Virus Infection Is Associated with Vascular Remodeling and Pulmonary Hypertension in Idiopathic Pulmonary Fibrosis. PLoS One 2013, 8(2)..

8. Tsukamoto K, Hayakawa H, Sato A, Chida K, Nakamura H, Miura K. Involvement of Epstein-Barr virus latent membrane protein 1 in disease progression in patients with idiopathic pulmonary fibrosis. Thorax. 2000; 55(11):958-61.

9. Hayakawa H, Shirai M, Uchiyama H, Imokawa S, Suda T, Chida K, Muro H. Lack of evidence for a role of Epstein-Barr virus in the increase of lung cancer in idiopathic pulmonary fibrosis. Respir Med. 2003;97(3):281-4.

10. Irving $W L$, Day $S$, Johnston ID. Idiopathic pulmonary fibrosis and hepatitis C virus infection. Am Rev Respir Dis. 1993;148(6 Pt 1):1683-4.

11. Wootton SC, Kim DS, Kondoh Y, Chen E, Lee JS, Song JW, Huh JW, Taniguchi H, Chiu C, Boushey H, et al. Viral infection in acute exacerbation of idiopathic pulmonary fibrosis. Am J Respir Crit Care Med. 2011;183(12): 1698-702.

12. Matsui R, Goldstein RH, Mihal K, Brody JS, Steele MP, Fine A. Type I collagen formation in rat type II alveolar cells immortalised by viral gene products. Thorax. 1994;49(3):201-6.

13. Isler JA, Skalet AH, Alwine JC. Human cytomegalovirus infection activates and regulates the unfolded protein response. J Virol. 2005;79(11):6890-9.

14. Lawson WE, Crossno PF, Polosukhin W, Roldan J, Cheng DS, Lane KB, Blackwell TR, Xu C, Markin C, Ware LB, et al. Endoplasmic reticulum stress in alveolar epithelial cells is prominent in IPF: association with altered surfactant protein processing and herpesvirus infection. Am J Phys Lung Cell Mol Phys. 2008;294(6):L1119-26.

15. Naik PN, Horowitz JC, Moore TA, Wilke CA, Toews GB, Moore BB. Pulmonary fibrosis induced by gamma-Herpesvirus in aged mice is associated with increased fibroblast responsiveness to transforming growth factor-beta. J Gerontol Series a-Biol Sci Med Sci. 2012;67(7):714-25.

16. Keating DT, Sadlier DM, Patricelli A, Smith SM, Walls D, Egan JJ, Doran PP. Microarray identifies ADAM family members as key responders to TGF-beta1 in alveolar epithelial cells. Respir Res. 2006;7:114.

17. Cayrol C, Flemington EK. Identification of cellular target genes of the Epstein-Barr virus transactivator Zta: activation of transforming growth factor beta igh3 (TGF-beta igh3) and TGF-beta 1. J Virol. 1995;69(7):4206-12.

18. Park GB, Kim D, Kim YS, Kim S, Lee HK, Yang JW, Hur DY. The Epstein-Barr virus causes epithelial-Mesenchymal transition in human corneal epithelial cells via Syk/Src and Akt/Erk signaling pathways. Invest Ophth Vis Sci. 2014; 55(3):1770-9.

19. Sides MD, Klingsberg RC, Shan B, Gordon KA, Nguyen HT, Lin Z, Takahashi T, Flemington EK, Lasky JA. The Epstein-Barr virus latent membrane protein 1 and transforming growth factor--beta1 synergistically induce epithelial-mesenchymal transition in lung epithelial cells. Am J Respir Cell Mol Biol. 2011:44(6):852-62.

20. Ozsolak F, Milos PM. RNA sequencing: advances, challenges and opportunities. Nat Rev Genet. 2011;12(2):87-98.

21. Raghu G, Collard HR, Egan JJ, Martinez FJ, Behr J, Brown KK, Colby TV, Cordier JF, Flaherty KR, Lasky JA, et al. An official ATS/ERS/JRS/ALAT statement: idiopathic pulmonary fibrosis: evidence-based guidelines for diagnosis and management. Am J Respir Crit Care Med. 2011;183(6):788824

22. Rabinovich El, Kapetanaki MG, Steinfeld I, Gibson KF, Pandit KV, Yu G, Yakhini Z, Kaminski N. Global methylation patterns in idiopathic pulmonary fibrosis. PLoS One. 2012;7(4):e33770.

23. Lino Cardenas CL, Henaoui IS, Courcot E, Roderburg C, Cauffiez C, Aubert S, Copin MC, Wallaert B, Glowacki F, Dewaeles E, et al. miR-199a-5p is upregulated during fibrogenic response to tissue injury and mediates TGFbeta-induced lung fibroblast activation by targeting caveolin-1. PLoS Genet. 2013;9(2):e1003291.

24. Vukmirovic M, Herazo-Maya JD, Blackmon J, Skodric-Trifunovic $V$, Jovanovic D, Pavlovic S, Stojsic J, Zeljkovic V, Yan X, Homer R, et al. Identification and validation of differentially expressed transcripts by RNA-sequencing of formalin-fixed, paraffin-embedded (FFPE) lung tissue from patients with idiopathic pulmonary fibrosis. BMC Pulm Med. 2017;17(1):15.

25. American Thoracic Society. Idiopathic pulmonary fibrosis: diagnosis and treatment. International consensus statement. American Thoracic Society (ATS), and the European Respiratory Society (ERS). Am J Respir Crit Care Med 2000, 161(2 Pt 1):646-664

26. Xu G, Strong MJ, Lacey MR, Baribault C, Flemington EK, Taylor CM. RNA COMPASS: a dual approach for pathogen and host transcriptome analysis of RNA-seq datasets. PLoS One. 2014;9(2):e89445.

27. Yin Q, Wang X, Fewell C, Cameron J, Zhu H, Baddoo M, Lin Z, Flemington EK. MicroRNA miR-155 inhibits bone morphogenetic protein (BMP) signaling and BMP-mediated Epstein-Barr virus reactivation. J Virol. 2010;84(13):631827.

28. Lin L, Fevery J, Hiem Yap S. A novel strand-specific RT-PCR for detection of hepatitis C virus negative-strand RNA (replicative intermediate): evidence of absence or very low level of HCV replication in peripheral blood mononuclear cells. J Virol Methods. 2002;100(1-2):97-105.

29. Caserta MT, Hall CB, Schnabel K, Lofthus G, McDermott MP. Human herpesvirus (HHV)-6 and HHV-7 infections in pregnant women. J Infect Dis. 2007;196(9):1296-303.

30. Folcik VA, Garofalo M, Coleman J, Donegan JJ, Rabbani E, Suster S, Nuovo A Magro CM, Di Leva G, Nuovo GJ. Idiopathic pulmonary fibrosis is strongly associated with productive infection by herpesvirus saimiri. Modern Pathol. 2014;27(6):851-62.

31. Kusko RL, Brothers JF 2nd, Tedrow J, Pandit K, Huleihel L, Perdomo C, Liu G, Juan-Guardela B, Kass D, Zhang S, et al. Integrated genomics reveals convergent Transcriptomic networks underlying chronic obstructive pulmonary disease and idiopathic pulmonary fibrosis. Am J Respir Crit Care Med. 2016;194(8):948-60.

32. Agoni L, Guha C, Lenz J. Detection of human endogenous retrovirus K (HERV-K) transcripts in human prostate Cancer cell lines. Front Oncol. 2013; 3:180.

33. Pandit KV, Corcoran D, Yousef H, Yarlagadda M, Tzouvelekis A, Gibson KF, Konishi K, Yousem SA, Singh M, Handley D, et al. Inhibition and role of let-7d in idiopathic pulmonary fibrosis. Am J Respir Crit Care Med. 2010;182(2):220-9.

34. Cheson BD, Pfistner B, Juweid ME, Gascoyne RD, Specht L, Horning SJ, Coiffier B, Fisher Rl, Hagenbeek A, Zucca E, et al. Revised response criteria for malignant lymphoma. J Clin Oncol. 2007;25(5):579-86.

35. Meliconi R, Andreone P, Fasano L, Galli S, Pacilli A, Miniero R, Fabbri M, Solforosi L, Bernardi M. Incidence of hepatitis C virus infection in Italian patients with idiopathic pulmonary fibrosis. Thorax. 1996:51(3):315-7.

36. Garson JA, Ring C, Tuke P, Tedder RS. Enhanced detection by PCR of hepatitis C virus RNA. Lancet. 1990;336(8719):878-9.

37. Ablashi DV, Dahlberg JE, Cannon GB, Fischetti G, Loeb W, Hinds W, Schatte C, Levine PH. Detection of antibodies to Herpesvirus saimiri late antigens in human sera. Intervirology. 1988;29(4):217-26.

38. Kowalczyk MJ, Danczak-Pazdrowska A, Szramka-Pawlak B, Zaba R, Silny W, Osmola-Mankowska A. Expression of selected human endogenous retroviral sequences in skin and peripheral blood mononuclear cells in morphea. Arch Med Sci. 2012;8(5):819-25.

39. Bergallo M, Pinon M, Galliano I, Montanari P, Dapra V, Gambarino S, Calvo PL: EBV induces HERV-K and HERV-W expression in pediatrics liver transplant recipients? Minerva Pediatr 2015.

40. Tycowski KT, Guo YE, Lee N, Moss WN, Vallery TK, Xie MY, Steitz JA. Viral noncoding RNAs: more surprises. Genes Dev. 2015;29(6):567-84.

41. Iwakiri D. Epstein-Barr virus-encoded RNAs: key molecules in viral pathogenesis. Cancers. 2014;6(3):1615-30.

42. Fok V, Mitton-Fry RM, Grech A, Steitz JA. Multiple domains of EBER 1, an Epstein-Barr virus noncoding RNA, recruit human ribosomal protein L22. RNA. 2006;12(5):872-82.

43. Gross H, Barth S, Pfuhl T, Willnecker V, Spurk A, Gurtsevitch V, Sauter M, Hu B, Noessner E, Mueller-Lantzsch N, et al. The NP9 protein encoded by the human endogenous retrovirus HERV-K (HML-2) negatively regulates gene activation of the Epstein-Barr virus nuclear antigen 2 (EBNA2). Int J Cancer. 2011;129(5):1105-15. 
44. Sutkowski N, Conrad B, Thorley-Lawson DA, Huber BT. Epstein-Barr virus transactivates the human endogenous retrovirus HERV-K18 that encodes a superantigen. Immunity. 2001;15(4):579-89.

45. Hsiao FC, Lin M, Tai A, Chen G, Huber BT. Cutting edge: Epstein-Barr virus transactivates the HERV-K18 superantigen by docking to the human complement receptor 2 (CD21) on primary B cells. J Immunol. 2006;177(4): 2056-60.

46. Cobbs CS, Harkins L, Samanta M, Gillespie GY, Bharara S, King PH, Nabors LB, Cobbs CG, Britt WJ. Human cytomegalovirus infection and expression in human malignant glioma. Cancer Res. 2002;62(12):3347-50.

47. Stragliotto G, Rahbar A, Solberg NW, Lilja A, Taher C, Orrego A, Bjurman B, Tammik C, Skarman P, Peredo I, et al. Effects of valganciclovir as an add-on therapy in patients with cytomegalovirus-positive glioblastoma: a randomized, double-blind, hypothesis-generating study. Int J Cancer. 2013; 133(5):1204-13.

48. Strong MJ, Blanchard E, Lin Z, Morris CA, Baddoo M, Taylor CM, Ware ML, Flemington EK. A comprehensive next generation sequencing-based virome assessment in brain tissue suggests no major virus - tumor association. Acta Neuropathol Commun. 2016;4(1):71.

49. Lopez-Mejia IC, Vautrot V, De Toledo M, Behm-Ansmant I, Bourgeois CF, Navarro CL, Osorio FG, Freije JM, Stevenin J, De Sandre-Giovannoli A, et al. A conserved splicing mechanism of the LMNA gene controls premature aging. Hum Mol Genet. 2011;20(23):4540-55.

50. Hjalgrim $\mathrm{H}$, Friborg J, Melbye M: The epidemiology of EBV and its association with malignant disease. In: Human Herpesviruses: Biology, Therapy, and Immunoprophylaxis. edn. Edited by Arvin A, Campadelli-Fiume G, Mocarski E, Moore PS, Roizman B, Whitley R, Yamanishi K. Cambridge; 2007

\section{Publisher's Note}

Springer Nature remains neutral with regard to jurisdictional claims in published maps and institutional affiliations.

Ready to submit your research? Choose BMC and benefit from:

- fast, convenient online submission

- thorough peer review by experienced researchers in your field

- rapid publication on acceptance

- support for research data, including large and complex data types

- gold Open Access which fosters wider collaboration and increased citations

- maximum visibility for your research: over $100 \mathrm{M}$ website views per year

At $\mathrm{BMC}$, research is always in progress.

Learn more biomedcentral.com/submissions 